\title{
Formulation and evaluation of voriconazole ophthalmic solid lipid nanoparticles in situ gel
}

\author{
Dinesh Kumar Pandurangan, Prathima Bodagala, Vijayaraj Kumar Palanirajan ${ }^{1}$, Saravanan Govindaraj ${ }^{2}$ \\ Department of Pharmaceutics, Hindu College of Pharmacy, Acharya Nagarjuna University, Guntur, ${ }^{2}$ Department of Pharmaceutical Analysis, \\ Bapatla College of Pharmacy, Bapatla, Andhra Pradesh, India, 'Department of Pharmaceutics, School of Pharmacy, University College \\ Sadaya International University, Kuala Lumpur, Malaysia
}

\begin{abstract}
In the present investigation, solid lipid nanoparticles (SLNs)-loaded in situ gel with voriconazole drug was formulated. Further, the formulation was characterized for $\mathrm{pH}$, gelling capacity, entrapment efficiency, in vitro drug release, drug content, and viscosity. Voriconazole is an antifungal drug used to treat various infections caused by yeast or other types of fungi. Film hydration technique was used to prepared SLNs from lecithin and cholesterol. Based on the entrapment efficiency $67.2-97.3 \%$ and drug release, the optimized formulation NF1 of SLNs was incorporated into in situ gels. The in situ gels were prepared using viscosity-enhancing polymers such as Carbopol and (hydroxypropyl) methyl cellulose (HPMC). Formulated SLN in situ gel formulations were characterized, which showed pH 4.9-7.1, drug content $65.69-96.3 \%$, and viscosity (100 rpm) 120-620 cps. From the characterizations given above, F6 was optimized and evaluated for microbial assay and ocular irritation studies. Microbial assay was conducted by the cup-plate method using Candida albicans as the test organism. An ocular irritation study was conducted on albino rabbits. The results revealed that there was no ocular damage to the cornea, conjunctiva, or iris. Stability studies were carried out on the F6 formulation for 3 months, which showed that the formulation had good stability. These results indicate that the studied SLNs-loaded in situ gel is a promising vehicle for ocular delivery.
\end{abstract}

Key words: In situ gel, ophthalmic, solid lipid nanoparticles (SLNs), voriconazole

\section{INTRODUCTION}

Ocular dosage forms are designed to be instilled onto the external surface of the eye, administered inside or adjacent to the eye. Ideal ophthalmic drug delivery must be able to sustain the drug release and to remain in the vicinity of the front of the eye for a prolonged period of time. ${ }^{[1]}$ Solid lipid nanoparticles (SLNs) are microscopic particles whose size is measured in nanometers $(\mathrm{nm})$. The size of a nanoparticle is $1-100 \mathrm{~nm} .^{[2,3]}$ SLNs are incorporated into in situ gels for sustained release of the drug, to prolong the residence time, and to increase the bioavailability of the drug.

\section{Address for correspondence:}

Mr. Dinesh Kumar Pandurangan,

Department of Pharmaceutics, Hindu College of Pharmacy,

Acharya Nagarjuna University, Guntur, Andhra Pradesh, India.

E-mail: dineshclbaid@gmail.com

\begin{tabular}{|l|l|}
\hline \multicolumn{2}{|c|}{ Access this article online } \\
\hline Quick Response Code: & Website: \\
\hline & \\
\cline { 2 - 2 } & www.jpionline.org \\
\hline
\end{tabular}

This new concept (in situ delivery) of producing a gel in situ was suggested for the first time in the early 1980s. "In situ" is a Latin phrase translated literally as "in position." In situ gel-forming systems can be described as low-viscosity solutions that undergo phase transition in the conjunctival cul-de-sac to form viscoelastic gels due to conformational changes of polymers in response to change in a specific physicochemical parameter such as ionic strength, $\mathrm{pH}$, or temperature. Gel dosage forms are successfully used as drug delivery systems, considering their ability to prolong drug release. ${ }^{[4]}$ In situ formulations prolong the precorneal resident time and improve ocular bioavailability of the drug. The in situ formulation exhibited good viscosity, drug content, and sustained drug release. ${ }^{[5,6]}$ Conventional liquid ophthalmic formulations demonstrate low bioavailability because of a constant lacrimal drainage in the eye..$^{[7,8]}$

This is an open access article distributed under the terms of the Creative Commons Attribution-NonCommercial-ShareAlike 3.0 License, which allows others to remix, tweak, and build upon the work non-commercially, as long as the author is credited and the new creations are licensed under the identical terms.

For reprints contact: reprints@medknow.com

How to cite this article: Pandurangan DK, Bodagala P, Palanirajan VK, Govindaraj S. Formulation and evaluation of voriconazole ophthalmic solid lipid nanoparticles in situ gel. Int J Pharma Investig 2016;6:56-62. 
Solution-to-gel phase transition may occur due to:

a. Physical stimuli: It includes change in temperature, electric field, and light;

b. Chemical stimuli: It includes changes in $\mathrm{pH}$ and ion activation from biological fluid; or

c. Biochemical stimuli: It includes changes in glucose level. ${ }^{[9,10]}$

Voriconazole is an antifungal drug used for treatment of various conditions caused by yeast or fungi. Voriconazole binds and inhibits ergosterol synthesis by inhibiting cytochrome P450mediated 14 alpha-lanosterol demethylation, an essential step in fungal ergosterol biosynthesis. The accumulation of 14 alphamethyl sterols correlates with the subsequent loss of ergosterol in the fungal cell wall and may be responsible for the antifungal activity. Voriconazole is available as powder for infusion, oral suspension, and tablet on the market.

In the present investigation, the main aim was to develop a solid lipid-loaded in situ gel formulation for ophthalmic drug delivery. The objective of this work was to improve precorneal retention time, thereby increasing therapeutic activity in a controlledrelease manner. Reducing the frequency of dosage will improve patient compliance.

\section{MATERIALS AND METHODS}

\section{Materials}

Voriconazole was obtained from FDC Ltd., Mumbai, Maharashtra. Carbopol 940 was purchased from CDH (P) Ltd., New Delhi. (hydroxypropyl) methyl cellulose (HPMC) K15M, ethylenediaminetetraacetic acid (EDTA), sodium chloride, and benzalkonium chloride were purchased from Loba Chem, Mumbai. All chemicals of analytical or pharmaceutical grade were used without further purification.

\section{Method}

\section{Preparation of nanolipids}

Nanolipids were prepared by film hydration technique. ${ }^{[1]}$ The mixture of vesicle-forming ingredients such as lecithin and cholesterol was dissolved in a volatile organic solvent (dichloromethane and methanol) in a round-bottom flask. The rotary evaporator was rotated at $60^{\circ} \mathrm{C}$ for $45 \mathrm{~min}$. Then the organic solvent was removed with gentle agitation and the organic solvent evaporated at $60^{\circ} \mathrm{C}$, leaving a thin film of lipid on the wall of the rotary flash evaporator. The aqueous phase containing voriconazole drug was added slowly with intermittent shaking of the flask at room temperature and sonicated for $30 \mathrm{~min}$. The obtained nanolipid solution was cooled by placing in the freezer. The composition of the nanolipid is presented in Table 1.

\section{Formulation of nanolipid in situ gel}

Nanolipid in situ gel was prepared on the basis of drug entrapment efficiency and morphology. The batch of nanolipid that gave maximum entrapment and good surface morphology was selected for preparation of in situ gel. ${ }^{[12]}$ Appropriate quantities of Carbopol 940 and HPMC K15M were sprinkled over nanolipid dispersion under constant stirring with a glass rod, taking care to avoid formation of lumps, and allowed to hydrate. Other ingredients such as benzalkonium chloride as preservative and sodium chloride to make gel formulations isotonic with tear fluid were added to the gel batches, incorporated in sufficient quantity to adjust the $\mathrm{pH}$. The compositions of various nanolipid in situ gels prepared are presented in Table 2.

\section{Preliminary studies}

\section{Drug polymer interaction studies}

Each drug excipient's compatibility was determined using infrared (IR) spectrum recorded on Bruker Vertex 70/70v (Germany) FTIR spectrophotometer. Samples of pure drug and physical mixtures of drug and excipients were scanned in the range of $400-4000 \mathrm{~cm}^{-1}$.

\section{Evaluation of SLNs}

\section{Vesicle shape and size analysis of SLNs}

The size and shape of the vesicles were determined using optical microscopy and scanning electron microscopy (SEM) (SEM Jeol JSM)-5800 California, USA. ${ }^{[8]}$

\section{Entrapment efficiency}

Separation of unentrapped drug from the nanolipid formulation was done by the ultracentrifugation method. Here, centrifuging of nanolipid dispersion was carried out at $14000 \mathrm{rpm}$ for $90 \mathrm{~min}$. The clear supernatant from the resulting solution was diluted appropriately using pH 7.4 phosphate buffer and analyzed by ultraviolet (UV) spectrophotometric method. ${ }^{[9]}$

\section{Drug release by diffusion}

Nanolipids equivalent to $1 \mathrm{mg}$ of voriconazole were accurately weighed and transferred to dialysis membrane. The membrane is

\begin{tabular}{lcccccc}
\multicolumn{6}{l}{ Table 1: Composition of nanolipid in situ gels } \\
\hline $\begin{array}{l}\text { Ingredients } \\
\text { (\% w/v or v/v) }\end{array}$ & NF1 & NF2 & NF3 & NF4 & NF5 & NF6 \\
\hline Drug & 0.05 & 0.05 & 0.05 & 0.05 & 0.05 & 0.05 \\
Lecithin & 0.05 & 0.05 & 0.1 & 0.05 & 0.15 & 0.2 \\
Cholesterol & 0.05 & 0.1 & 0.05 & 0.15 & 0.1 & 0.05 \\
Methanol & 7.5 & 7.5 & 7.5 & 7.5 & 7.5 & 7.5 \\
Water & 10 & 10 & 10 & 10 & 10 & 10 \\
\hline
\end{tabular}

\begin{tabular}{lcccccc}
\multicolumn{6}{l}{ Table 2: Composition of nanolipid in situ gels } \\
\hline $\begin{array}{l}\text { Ingredients } \\
\text { (\% w/v or v/v) }\end{array}$ & F1 & F2 & F3 & F4 & F5 & F6 \\
\hline Drug & & & & & & \\
Lecithin & 0.05 & 0.05 & 0.05 & 0.05 & 0.05 & 0.05 \\
Cholesterol & 0.05 & 0.05 & 0.05 & 0.05 & 0.05 & 0.05 \\
Methanol & 0.05 & 0.05 & 0.05 & 0.05 & 0.05 & 0.05 \\
Water & 7.5 & 7.5 & 7.5 & 7.5 & 7.5 & 7.5 \\
HPMC & 10 & 10 & 10 & 10 & 10 & 10 \\
Carbopol & 0.2 & 0.2 & 0.4 & 0.4 & 0.3 & 0.2 \\
EDTA & 0.2 & 0.4 & 0.2 & 0.4 & 0.2 & 0.3 \\
Benzolkonium & 0.1 & 0.1 & 0.1 & 0.1 & 0.1 & 0.1 \\
chloride & 0.01 & 0.01 & 0.01 & 0.01 & 0.01 & 0.01 \\
Sodium chloride & 0.9 & 0.9 & 0.9 & 0.9 & 0.9 & 0.9 \\
Phosphate buffer & 100 & 100 & 100 & 100 & 100 & 100 \\
\hline
\end{tabular}


tied with threads and placed in a $250 \mathrm{~mL}$ conical flask containing $100 \mathrm{~mL}$ phosphate buffer ( $\mathrm{pH}$ 7.4). The flask was kept in an incubator at $37^{\circ} \mathrm{C}, 1 \mathrm{~mL}$ samples were withdrawn at regular intervals, and $1 \mathrm{~mL}$ of phosphate buffer was added to the release medium to replenish it. Similarly, the release of voriconazole from nanolipids was determined spectrophotometrically at 272 nm (Shimadzu 1800, Japan) after suitable dilution. ${ }^{[13]}$

\section{Characterization of SLNs in situ gel Visual appearance and $\mathrm{pH}$}

Visual appearance and clarity were observed for the presence of any particular matter. The $\mathrm{pH}$ was measured using $\mathrm{pH}$ meter. The $\mathrm{pH}$ was noted by bringing the electrode near the surface of the formulations and allowing it to equilibrate for $1 \mathrm{~min} .{ }^{[14,15]}$

\section{In vitro gelation study}

The developed in situ gel was assessed for its gelling capacity. The gelling capacity was determined by placing a drop of the polymer solution in a vial containing $2 \mathrm{~mL}$ of freshly prepared simulated tear fluid (STF) equilibrated at $37^{\circ} \mathrm{C}$. The time taken for gelation and dissolution by the developed gel was noted. ${ }^{[16-18]}$

\section{In vitro drug release}

In vitro release studies of voriconazole nanolipid in situ gel were carried out at $37^{\circ} \mathrm{C}$ using phosphate buffer ( $\left.\mathrm{pH} 7.4\right)$ as the release medium. Nanolipid in situ gel $(5 \mathrm{~mL})$ containing voriconazole was accurately weighed and transferred to the dialysis membrane. The gel was gently pushed down to the surface of the dialysis membrane to make contact with the membrane. Phosphate buffer ( $1 \mathrm{~mL}, \mathrm{pH} 7.4$ ) was added to the reservoir compartment to wet the gel; dialysis membrane was just immersed in the phosphate buffer, which acted as the receiving compartment. The receiving compartment was placed in magnetic stirrer (100 rpm, Remi, Mumbai, India) at $37^{\circ} \mathrm{C}$. Samples $(1 \mathrm{~mL})$ were withdrawn from the receiving compartment at regular intervals, and the amount of voriconazole released from the nanolipid in situ gel was determined using a spectrophotometer at $272 \mathrm{~nm}$ (Shimadzu 1800). After each withdrawal of sample, an equal quantity of phosphate buffer was added to the receiving compartment to replenish it. ${ }^{[19]}$

\section{Estimation of drug content}

Nanolipid suspension equivalent to $50 \mathrm{mg}$ was taken into a standard volumetric flask and mixed with $100 \mathrm{~mL}$ propan-1-ol by shaking. Then $0.1 \mathrm{~mL}$ of this solution was diluted to $10 \mathrm{~mL}$ with phosphate buffer ( $\mathrm{pH}$ 7.4). The absorbance of the resulting solution was measured at $272 \mathrm{~nm}$ and the drug content was calculated from the calibration curve. Concentrations of drug were calculated from the standard calibration curve prepared in phosphate buffers (pH 7.4). ${ }^{[10,20]}$

\section{Viscosity study}

The viscosity of the gels was studied on Brookfield viscometer (DV-II + Pro Viscometer, Middleboro, USA) by using CPE-42 spindle at $10 \mathrm{rpm}, 20 \mathrm{rpm}, 50 \mathrm{rpm}$, and $100 \mathrm{rpm}^{\left[{ }^{[21]}\right.}$

\section{Antimicrobial activity}

Antimicrobial study was carried out to check the antimicrobial efficiency of voriconazole in situ gel. The test organisms used were Candida albicans; the growth medium used was nutrient agar. The cup-plate method was used to carry out antimicrobial study. The method is based on the principle of diffusion of drug from vertical cup through solidified agar layer in Petri plate. Sterile solution of ciprofloxacin (on the market) eye drops was used as a standard. The standard solution and the developed formulations (test solution) were taken into separate cups bored into sterile nutrient agar previously seeded with Candida albicans organisms. The gels were allowed to diffuse for $2 \mathrm{~h}$ and then the plates were incubated for $24 \mathrm{~h}$ at $37^{\circ} \mathrm{C}$. The zone of inhibition (ZOI) was compared with that of the standard. ${ }^{[22]}$

\section{Ocular irritation studies}

The optimized formulation was evaluated for in vivo performance in an animal model (albino rabbits). The protocol was approved by the Animal Ethics Committee (1722/PO/A/13/IAEC/CPCSEA EXP-030). Animals were housed at room temperature $\left(27^{\circ} \mathrm{C}\right)$ and fed with standard diet and water. The albino rabbits, each weighing 2-3 kg, were placed in cages and the eyes were marked as test and control. The control eye received no sample and the test eye received the formulation $(0.5 \mathrm{~mL})$, and the eyes were observed at $1 \mathrm{~h}, 24 \mathrm{~h}, 48 \mathrm{~h}, 72 \mathrm{~h}$, and 1 week after exposure. Ocular change was graded by a scoring system that includes rating any alterations to the eyelids, conjunctiva, cornea, and iris. Rabbits were observed periodically for redness, swelling, and watering of the eye. ${ }^{[8,23]}$ Evaluation was carried out according to the Draize technique.

\section{Accelerated stability studies}

The optimized nanolipid dispersion with the highest entrapment efficiency was placed in vials and sealed with aluminum foil for a short-term accelerated stability study at $25 \pm 2{ }^{\circ} \mathrm{C} / 60 \pm 5 \%$ relative humidity $(\mathrm{RH})$ as per modified International Conference on Harmonisation (ICH) guidelines. Samples were analyzed every 90 days for drug content. ${ }^{[24]}$

\section{RESULTS AND DISCUSSION}

Drug polymer interaction was studied using the IR spectrum. The Fourier transform (FT)-IR spectra of the pure drug and the mixture of drug and polymers are shown in Figures 1 and 2. From the spectral study [Tables 3 and 4], it was observed that there was no significant change in the peaks of pure drug and of drug

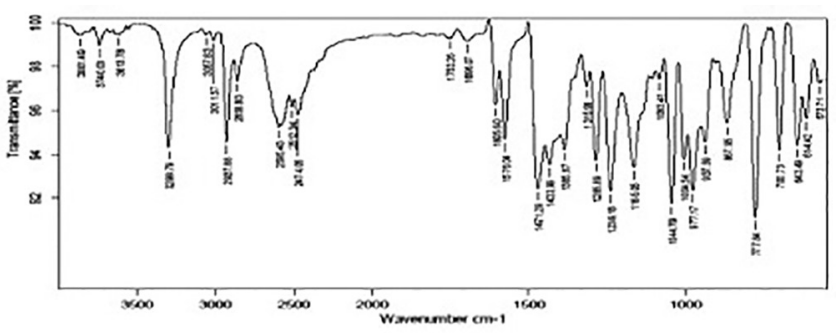

Figure 1: IR spectrum of drug 
polymer mixture. Hence, no specific interaction was observed between the drug and the polymers used in the formulations.

SEM images showed that most of the vesicles formed were spherical in shape [Figures 3 and 4]. The nature of lipids played a major role in drug entrapment efficiency. The entrapment efficiencies were within the range of $67.2-97.3 \%$ [Table 5]. NF1 had shown the highest entrapment efficiency of $97.3 \%$. NF5 showed the lowest entrapment efficiency of $67.2 \%$. The other formulations NF2, NF3, NF4, and NF6 showed 87\%, 69\%, 77.56\%, and 89.63\% entrapment efficiency, respectively [Figure 5].

The drug release from nanolipids occurred for $10 \mathrm{~h}$ in $\mathrm{pH}$ 7.4 buffer. The drug release of nanolipids was within the range of 79.8-99.0\%. From the drug release data, it was found that NF1 released maximum drug $(99.0 \%)$ compare to other formulations [Figure 6]. NF1 was selected as the best SLN formulation and incorporated into in situ gel for further studies. An equal ratio of lecithin and cholesterol was responsible for good entrapment efficiency and drug release.

Visual appearance and clarity were observed for the presence of any particular matter. The $\mathrm{pH}$ of nanoparticles in situ gel was detected by using digital $\mathrm{pH}$ meter. Nanolipid in situ gels' $\mathrm{pH}$ range was $\mathrm{pH}$ 5-7.4 [Table 6]. Nanolipid in situ gel showed maximum $\mathrm{pH}$ value (7.1) for $\mathrm{F} 6$ formulation. The $\mathrm{pH}$ of the reported formulations was nonirritable to the eye. This reflects that the gel will be nonirritant to the eye surface.

The gelling capacity was determined by freshly prepared simulated tear fluid (STF). Gelation study revealed that the formulations $\mathrm{F} 1$ and $\mathrm{F} 3$ gelled slowly and dissolved rapidly within

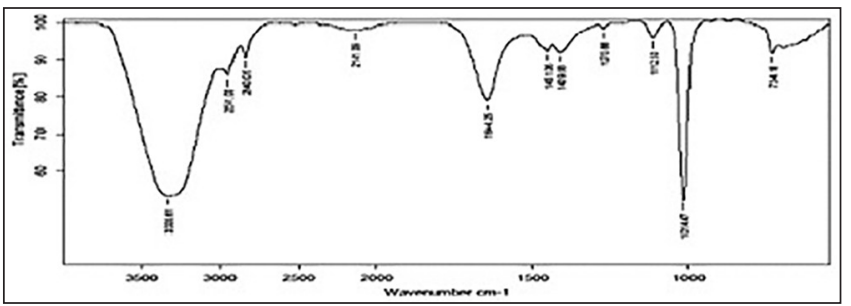

Figure 2: IR spectrum of drug and excipients

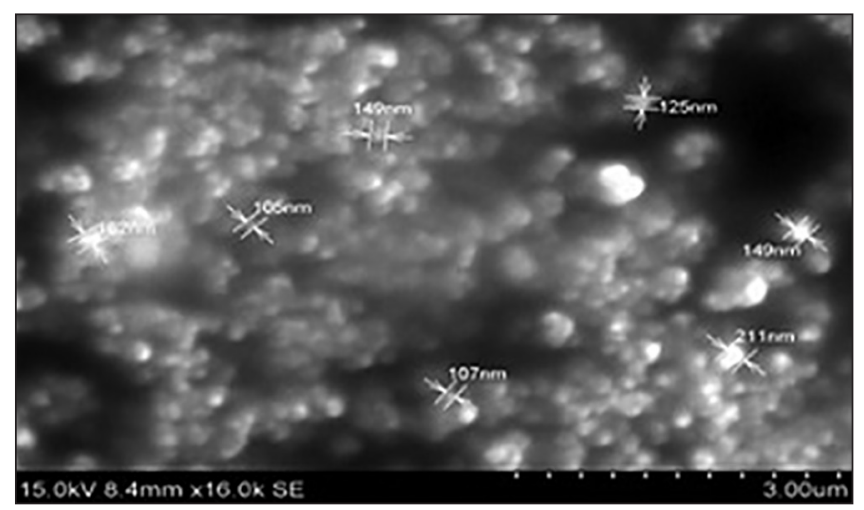

Figure 4: SEM image of voriconazole
1 h. Formulations F2 and F5 showed immediate gelation and remained for a few hours. Formulations F4 and F6 exhibited immediate gelation and remained for 2-4 h [Table 7].

The drug release studies of nanolipid in situ gel with voriconazole were performed for $24 \mathrm{~h}$ in $\mathrm{pH} 7.4$ phosphate buffer. From the

\begin{tabular}{lcc} 
Table 3: IR spectral data of voricanazole \\
\hline Group & \multicolumn{3}{c}{ Frequency } \\
\cline { 2 - 3 } & Expected & Obtained \\
\hline C=N & $1630-1690$ & 1644 \\
C=C & $1450-1600$ & 1451 \\
C-F & $1000-1400$ & 1270 \\
C-N & $1000-1400$ & 1112 \\
\hline
\end{tabular}

\begin{tabular}{lcc} 
Table 4: IR spectral data of nanolipid in situ gel \\
\hline Group & \multicolumn{2}{c}{ Frequency } \\
\cline { 2 - 3 } & Expected & Obtained \\
\hline C=N & $1630-1690$ & 1696 \\
C=C & $1450-1600$ & 1433 \\
C-F & $1000-1400$ & 1285 \\
C-N & $1000-1400$ & 1165 \\
\hline
\end{tabular}

Table 5: Entrapment efficiency of nanolipid in situ gels

\begin{tabular}{lc}
\hline Formulation & Entrapment efficiency (\%) \\
\hline NF1 & $97.30 \pm 0.57$ \\
NF2 & $87.00 \pm 0.84$ \\
NF3 & $69.00 \pm 0.39$ \\
NF4 & $77.56 \pm 0.86$ \\
NF5 & $67.20 \pm 0.29$ \\
NF6 & $89.63 \pm 0.25$ \\
\hline *Values expressed as mean $\pm S D, n=3, S D=$ Standard deviation
\end{tabular}

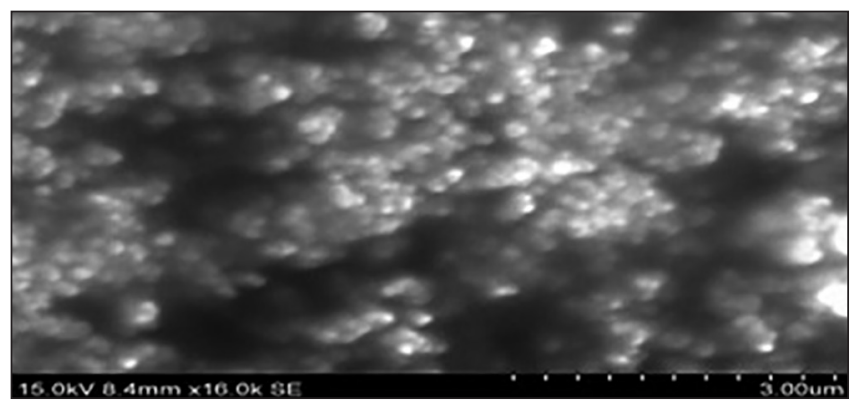

Figure 3: SEM image of voriconazole

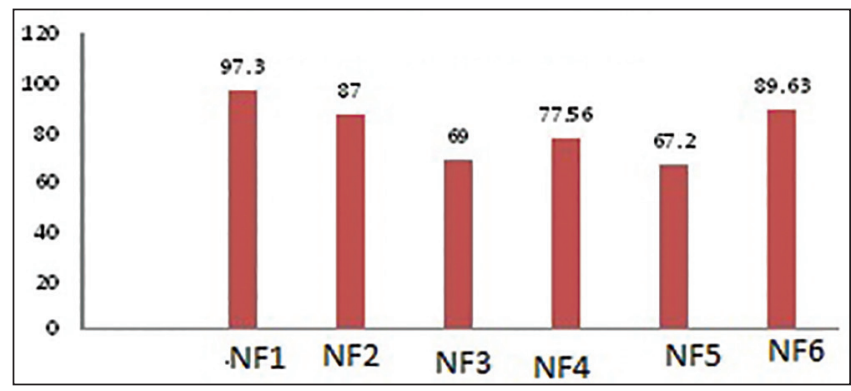

Figure 5: Comparative entrapment efficiency of nanolipids 
release data, it was found that drug release from the formulation F6 was $91.24 \%$ for $24 \mathrm{~h}$. The cumulative percentages of drug released from various SLN formulations are shown in Figure 7. Formulation F6 showed steadier drug release than other formulations; moreover, release of the drug was in a controlled manner. Release pattern of the drug was mainly influenced by the polymer ratio and the viscosity of the gel. Hence, F6 was selected as the best SLNs in situ gel formulation.

Formulations were analyzed for drug content spectrophotometrically at $272 \mathrm{~nm}$. All the formulations exhibited fairly uniform drug content. The drug contents of all formulations were in a range of 87.03-96.36\% [Table 8]. Out of several tested formulations, F6 showed the highest drug content $(96.36 \%)$.

Viscosity is an important parameter for characterizing the SLNs in situ gel formulations, as it affects the release of the drug. The highest viscosity, for gel F6 formulation, led to retarded drug release up to a considerable extent $(97.24 \%)$ in $24 \mathrm{~h}$ when compared with other formulations. Low-viscosity formulations showed highest drug release. Intermediate viscosity of formulations has shown maximum retardation of drug release due to the viscous nature of the polymers. Carbopol 940 and HPMC as polymer system have contributed majorly toward building the viscosity of the formulation. Viscosities of the prepared SLNs in situ gel formulations were found to be in the range 120-915 cps [Table 9].

The optimized nanolipid in situ gel formulations F6 showed antimicrobial activity when tested microbiologically by the cup-plate technique. The prepared nanolipid in situ gel formulation F6 inhibited the growth of Candida albicans. ZOI

\begin{tabular}{lcc}
\multicolumn{3}{l}{ Table 6: Visual appearance and $\mathbf{p H}$} \\
\hline Formulations & Visual appearance & $\mathbf{p H}^{*}$ \\
\hline F1 & Cloudy & $5.9 \pm 0.070$ \\
F2 & Clear & $5.1 \pm 0.141$ \\
F3 & Clear & $6.2 \pm 0.749$ \\
F4 & Cloudy & $4.9 \pm 0.021$ \\
F5 & Clear & $6.1 \pm 0.728$ \\
F6 & Clear & $7.1 \pm 0.145$ \\
\hline
\end{tabular}

"Values expressed as mean $\pm \mathrm{SD}, n=3, \mathrm{SD}=$ Standard deviation

Table 7: Gelling capacity of nanolipid in situ gel Formulations Gelation capacity

\begin{tabular}{lc}
\hline F1 & + \\
F2 & ++ \\
F3 & + \\
F4 & +++ \\
F5 & ++ \\
F6 & +++ \\
\hline
\end{tabular}

+ Gelation slow and dissolves rapidly, ++Gelation immediate and remains for short period of time, +++Gelation immediate and remains for extended period of time

\section{Table 8: Drug content estimation of nanolipid} in situ gel

\begin{tabular}{lc} 
Formulations & Drug content $(\%)^{\star}$ \\
\hline F1 & $87.03 \pm 0.34$ \\
F2 & $75.83 \pm 0.56$ \\
F3 & $65.69 \pm 0.48$ \\
F4 & $87.79 \pm 0.57$ \\
F5 & $80.00 \pm 0.46$ \\
F6 & $96.36 \pm 0.78$ \\
\hline
\end{tabular}

*Values expressed as mean $\pm S D, n=3, S D=$ standard deviation

\section{Table 9: Viscosity profile of nanolipid in situ gel}

\begin{tabular}{|c|c|c|c|c|c|c|}
\hline \multirow{2}{*}{$\begin{array}{l}\text { Angular velocity } \\
\text { (rpm) }\end{array}$} & \multicolumn{6}{|c|}{ Viscosity (CPS) } \\
\hline & F1 & F2 & F3 & F4 & F5 & F6 \\
\hline 10 & $427 \pm 1.992$ & $672 \pm 1.557$ & $695 \pm 1.192$ & $803 \pm 0.603$ & $732 \pm 0.564$ & $915 \pm 1.798$ \\
\hline 20 & $365 \pm 1.894$ & $445 \pm 1.119$ & $654 \pm 0.213$ & $798 \pm 1.921$ & $675 \pm 0.589$ & $827 \pm 0.690$ \\
\hline 50 & $243 \pm 1.669$ & $332 \pm 1.995$ & $364 \pm 0.7071$ & $623 \pm 0.131$ & $432 \pm 1.529$ & $750 \pm 1.482$ \\
\hline 100 & $154 \pm 1.454$ & $243 \pm 0.811$ & $120 \pm 0.698$ & $263 \pm 0.828$ & $255 \pm 0.858$ & $620 \pm 0.426$ \\
\hline
\end{tabular}

*Values expressed as mean $\pm S D, n=3$, SD = Standard deviation

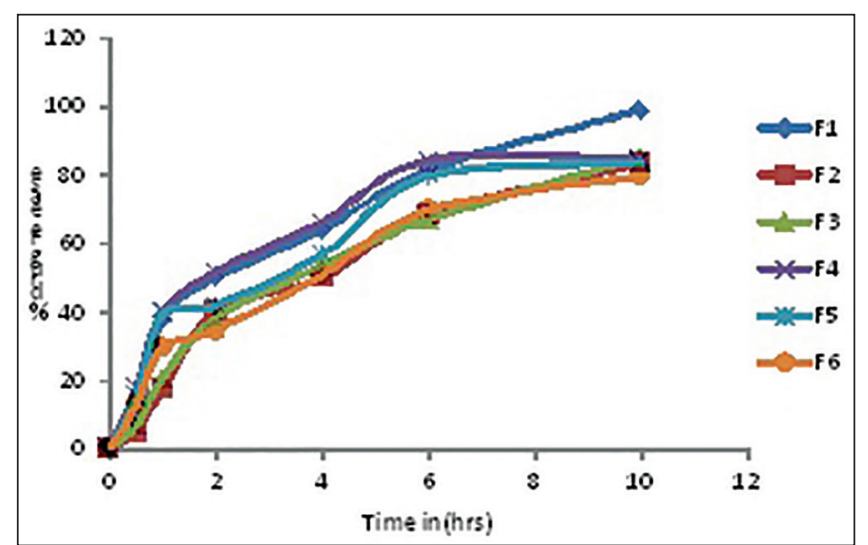

Figure 6: In vitro drug release of nanoparticles

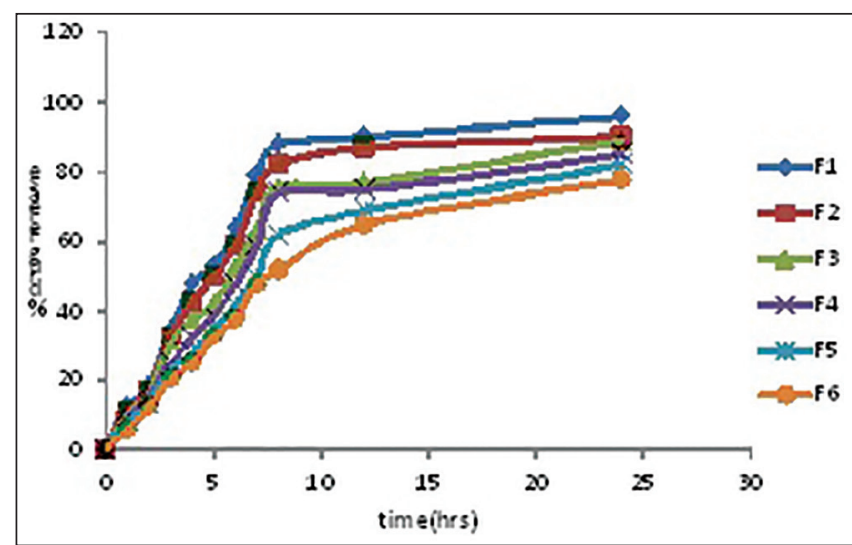

Figure 7: In vitro release profile of nanoparticles in situ gel 
was measured by using zone reader in $\mathrm{mm}$. The voriconazole retained its antimicrobial efficacy when formulated as an in situ gelling system [Table 10 and Figure 8]. F6 formulation displayed the maximum ZOI of $40 \mathrm{~mm}$. This proves that the test formulation has better efficacy and has an excellent antimicrobial property.

The results of the ocular irritation studies indicate that the formulations have no average score (zero) according to the Draize scale [Table 2]. Excellent ocular tolerance was noted; no ocular damage or abnormal clinical signs in the cornea, iris, or conjunctiva were visible [Table 11].

The stability studies of SLNs in situ gel were performed at $5 \pm$ $2^{\circ} \mathrm{C}$ and $25 \pm 2{ }^{\circ} \mathrm{C} / 60 \pm 5 \% \mathrm{RH}$ for 3 months. The formulations were examined visually for precipitation. The drug content was determined every 30 days for 3 months. It was observed that there was no change in the physical appearance of the formulation. The drug content was analyzed and there were marginal differences between the formulations kept at different temperatures [Table 12]. SLNs in situ formulations retained good stability throughout the study.

\begin{tabular}{llc}
\multicolumn{4}{l}{ Table 10: ZOI of microbial assay } \\
\hline Formulation $(\mathbf{1 0} \mu \mathrm{g} / \mathrm{mL})$ & Microorganism & ZOI \\
\hline Nanolipid in situ gel & Candida albicans & $40 \mathrm{~mm}$ \\
Marketed eye drops & Candida albicans & $32 \mathrm{~mm}$ \\
\hline
\end{tabular}

\section{Table 11: Ocular irritation study}

\begin{tabular}{llll}
\hline Eye part & Cornea & Iris & Conjunctivae \\
\hline Observation & Normal & Normal & Normal \\
\hline
\end{tabular}

\begin{tabular}{|c|c|c|c|c|}
\hline \multirow[t]{2}{*}{ Conditions } & \multicolumn{4}{|c|}{ Drug content (\%) } \\
\hline & Initial & 1 month & 2 months & 3 months \\
\hline $\begin{array}{l}5 \pm 2^{\circ} \mathrm{C} \\
25 \pm 2^{\circ} \mathrm{C} / 60 \pm 5 \% \mathrm{RH}\end{array}$ & $\begin{array}{l}96.36 \\
96.36\end{array}$ & $\begin{array}{l}96.31 \\
96.29\end{array}$ & $\begin{array}{l}96.27 \\
96.21\end{array}$ & $\begin{array}{l}96.15 \\
96.12\end{array}$ \\
\hline
\end{tabular}

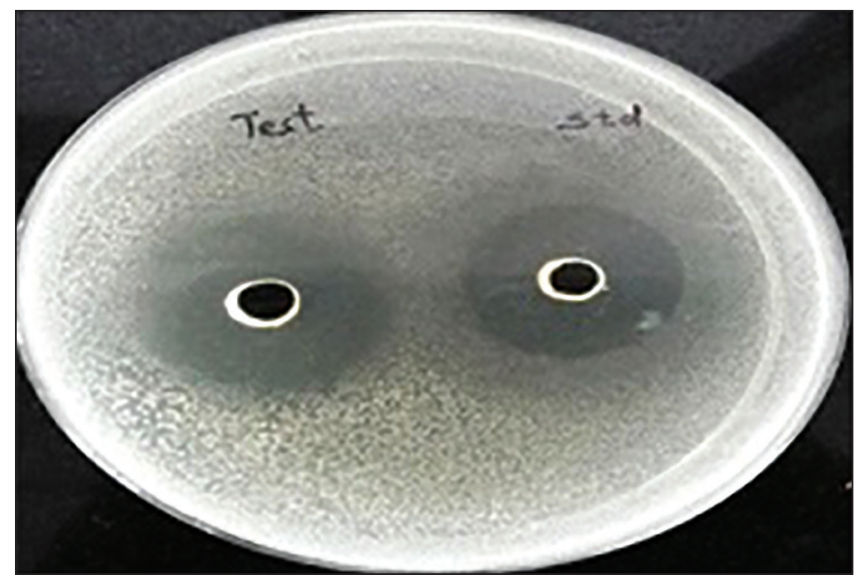

Figure 8: ZOI of voriconazole

\section{CONCLUSION}

It can been concluded that incorporation of voriconazole-loaded SLNs with in situ gel was formulated successfully. The SLNs in situ gel formulations was prepared using various polymers such as Carbopol 940 and HPMC, which release the drug in a sustained manner to decrease dosing frequency and to maintain prolonged therapeutic effect. The SLNs in situ gel formulation produced an excellent ZOI in microbial assay. Ocular irritation studies in rabbits showed no irritation. From the above study, it can be concluded that the use of SLNs-loaded in situ gel provides a number of advantages over the conventional ocular dosage forms. Sustained and prolonged release makes the delivery system more reliable and more acceptable to the patients, and increases patient compliance. The SLNs in situ gel formulation can be developed as an acceptable and excellent formulation for ocular drug delivery. However, various in vivo studies and clinical trials are required for it to be developed as an ocular dosage formulation.

\section{Financial support and sponsorship} Nil.

\section{Conflicts of interest}

There are no conflicts of interest.

\section{REFERENCES}

1. Abdul Hasan Sathali A, Mohanambal E, Arun K. Formulation and evaluation of $\mathrm{pH}$ triggered in situ gelling system of levofloxacin. Indian J Pharm Educ Res 2011;45:58-64.

2. RathoreKS,NemaRK.http://www.articlesbase.com/visionarticles/ ophthalmic-nanoparticles-drug-deliverysystems-1273176.html. [Last accessed on 2010 May 27].

3. Kumar S, Haglund BO, Himmelstein KJ. In situ-forming gels for ophthalmic drug delivery. J Ocul Pharmacol 1994;10:47-56.

4. Nanjawade BK, Manvi FV, Manjappa AS. In situ-forming hydrogels for sustained ophthalmic drug delivery. J Control Release 2007;122:119-34.

5. Nirmal HB, Bakliwal SR, Pawar SP. In situ gel: New trends in controlled and sustained drug delivery system. Int J Pharm Tech Res 2010;2:1398-408.

6. Kaur IP, Singh M, Kanwar M. Formulation and evaluation of ophthalmic preparations of acetazolamide. Int J Pharm 2000;199:119-27.

7. Gokulgandhi MR, Parikh JR, Megha Barot M, Modi DM. A pH triggered in situ gel forming ophthalmic drug delivery system for tropicamide. Drug Deliv Technol 2007;5:44-9.

8. Lavanya B, Indira S, Srinivas P. Formulation and evaluation of ocular niosomal in situ gels of linezolid. Int J Pharm Sci Res 2014;4:1367-75.

9. Nagalakshmi S, Seshank, Ramaswamy R, Shanmuganathan S. Formulation and evaluation of stimuli sensitive $\mathrm{pH}$ triggered in-situ gelling system of fluconazole in ocular drug delivery. Int J Pharm Sci Res 2014;5:1339-44.

10. Nanjawade BK, Manjappa AS, Murthy RS, Pol YD. A novel pH triggered in situ gel for sustained ophthalmic delivery of ketorlac tromithamine. Asian J Pharm Sci 2009;4:189-99.

11. Moorthi C, Krishnan K, Manavalan R, Kathiresan K. Preparation and characterization of curcumin-piperine dual drug loaded nanoparticles. Asian Pac J Trop Biomed 2012;2:841-8. 
12. Abraham S, Furtado S, Bharath S, Basavaraj BV, Deveswaran R, Madhavan V. Sustained ophthalmic delivery of ofloxacin from an ionactivated in situ gelling system. Pak J Pharm Sci 2009;22:175-9.

13. Padma J, Preetha K, Karthika, Rekha NR, Elshafie K. Formulation and evaluation of in situ ophthalmic gels of diclofenac sodium. J Chem Pharm Res 2010;2:528-35.

14. Srividya B, Cardoza RM, Amin PD. Sustained ophthalmic delivery of ofloxacin from a pH triggered in situ gelling system. J Control Release 2001;73:205-11.

15. Kumar SR, Himmestein KJ. Modification of in situ gelling behavior of carbopol solutions by hydroxyl propyl methyl cellulose. J Pharm Sci 1995;84:344-8.

16. Nagesh C, Patil M, Chandrashekhara S, Sutar R. A novel in situ gel for sustained ophthalmic delivery of ciprofloxacin hydrochloride and dexamethasone - Design and characterization. Der Pharmacia Lettre 2012;4:821-7.

17. Darwhekar G, Jain P, Jain DK, Agrawal G. Development and optimization of dorzolamide hydrochloride and timolol maleate in situ gel for glaucoma treatment. Asian J Pharm Anal 2011;1:93-7.

18. Pandey A, Mali PY, Sachdeva D, Patel DK, Ramesh R. Development and optimization of levobunolol hydrochloride in-situ gel for glaucoma treatment. Int $\mathrm{J}$ Pharm Biol Arch 2010;1:134-9.

19. Mohan EC, Kandukuri JM, Allenki V. Preparation and evaluation of in-situ-gels for ocular drug delivery. J Pharm Res 2009;2: 1089-94.

20. Carlfors J, Edsman K, Petersson R, Jörnving K. Rheological evaluation of gelrite in situ gels for ophthalmic use. Eur J Pharm Sci 1998;6:113-9.

21. Wamorkar V, Varma MM, Manjunath SY. Formulation and evaluation of stomach specific in-situ gel of metoclopramide using natural, bio-degradable polymers. Int J Res Pharm Biomed Sci 2011;2:193-201.

22. Cohen S, Lobel E, Trevgoda A, Peled Y. A novel in situ-forming ophthalmic drug delivery system from alginates undergoing gelation in the eye. J Control Rel 1997;44:201-8.

23. OECD. Acute Eye Irritation/Corrosion Guideline for Testing of Chemicals No. 405. Organisation for Economic Cooperation and Development, Paris. 2012.

24. Ruel-Gariépy E, Leroux JC. In situ-forming hydrogels--review of temperature-sensitive systems. Eur $\mathrm{J}$ Pharm Biopharm 2004;58:409-26. 